\title{
Presenting and perceiving humour in Estonian tourism settings
}

\author{
Marit Piirman \\ University of Tartu, Pärnu College, Estonia \\ marit.piirman@ut.ee
}

\section{Katrin Saks}

University of Tartu, Estonia

katrin.saks@ut.ee

\begin{abstract}
Humour plays a significant role in everyday interactions. Individuals perceive humour differently and experience various emotions, from exaltation to umbrage. Therefore, providing humorous communication in customer service is challenging. The aim of this study was to investigate the perception of humour in a tourism customer service context. In the first part of the study, representatives of Estonian tourism companies were asked their opinions about using humour in communication with their clients. They provided examples of the use of humour in customer service situations, which were then evaluated by potential tourists in the second part of the study. The results of the evaluation were analysed in relation to the respondents' sense of humour. The findings were discussed in line with the four implicatures of humour.
\end{abstract}

Keywords: tourism, perception of humour, sense of humour, customer service, Estonia).

\section{Introduction}

Historically, travellers were strangers, and therefore considered with distrust and hesitation by local people. In early hotels, hosts used humour to convert strangers into friends (Ball \& Johnson 2011: 199-202). While tourism brings together people from different national and cultural backgrounds, amusing them is a challenge for service providers (Pabel \& Pearce 2019). Humour strengthens the relationship between the service provider and their customers (Mathies, Chiew, \& Kleinaltenkamp 2016), and therefore can be considered a social currency for connecting people through shared experience and memories (Neuendorf, Rudd, Palisin \& Pask 2015).

Humour is widely recognised to build social solidarity. But when the laughter is not shared, it leads to exclusion as much as inclusion (Smith 2009). Particularly in customer service settings, it is important to understand how humour is perceived by customers to ensure we do not hurt 
anyone but amuse them; therefore, using humour must be based on a firm foundation of knowledge, professionalism, and empathy (Rowe \& Regehr 2010).

Different languages and cultural backgrounds may result in amusing miscommunications which offer opportunities to investigate humour in multicultural communication situations (Pabel 2019). However, the deliberate use of humour with visitors from a different culture might not always be understood. People from different cultures perceive humour differently, so what is funny for people in one culture can be boring, humourless or even offensive in another (Alharthi 2014). Different cultural backgrounds require that the orientation, perception and interpretation of humour by different nationalities be considered (Booth-Butterfield \& Kanjeva 2018).

The aim of this study is three-fold. Firstly, the study aims to clarify the use of humour Estonian tourism service providers perceive as appropriate to use in customer service situations, and secondly, to investigate how potential visitors to Estonia perceive humour used in Estonian tourism companies. Thirdly, it explores which clusters are formed based on the respondents' sense of humour and how this relates to their perception of the humour used in companies in the Estonian tourism sector. Based on the aim, the following research questions were posed:

1. What are Estonian tourism service providers' opinions on the use of humour in communications with tourists?

2. How do international visitors perceive the humour used in Estonian tourism companies?

3. Do tourists perceive the humorous examples used by Estonian tourism companies as funny and how does this relate to their own sense of humour?

\section{Theoretical background}

\subsection{Theoretical concepts of humour}

The identification of humour may be a difficult task (Bell 2007). According to Neuendorf et al. (2015), there are four independent mechanisms of humour: disparagement, incongruity, arousalbased humour and social currency humour, which have been studied as a means of building and maintaining relationships. How these mechanisms appear may depend on different factors. Humour theories are declared as mixed theories (Pearce \& Pabel 2015: 10-12). According to Lynch (2002), the only way to understand why humour is used, why a joke is funny or the motivation behind humour, is to look at the interpretations of the three major theories (superiority, incongruity and relief humour motivations) of humour motivation together, overlapping with each other. McGhee (1979, cited in Pearce and Pabel, 2015) explains the superiority theory as associated with jokes about others, while the incongruity theory involves humour bringing together two unrelated ideas, concepts or situations. The relief theory can be dated back to Freud (1905, cited in Pearce and Pabel, 2015), who said that laughter is used to release built-up nervous energy.

Using humour involves two parties - the speaker with the intention to joke and the recipient who interprets the humour and responds accordingly. The recipients' perception of the humour and response may depend on several factors including their personal sense of humour, temporary mood, cultural background and the language of interaction. Humour can be rejected, even if people understand and find it amusing, because it is not socially acceptable (Hale 2018).

The perception of humour and the humour response have been framed using different theories. Hay (2001) distinguishes four implicatures of receiving and perceiving humour. The term implicature, first coined by Grice (1975), denotes an indirect speech act of implying a meaning beyond the literal sense of what is explicitly stated. The first three implicatures by Hay 
(2001) - recognition, understanding, and appreciation - are related in terms of scale, understanding involving recognition, and appreciation involving recognition and understanding. The fourth implicature, agreement, assumes recognition and understanding but not necessarily appreciation.

Recognition refers to identifying an attempt at humour. Even though it may not assume the use of support strategies by the recipient, it tests his ability to identify the text as humour. Failed humour is not perceived if it was not recognised as an attempt at humour (Eisterhold 2007) or it may result in loss of face (Zajdman, 1995). Carrell (1997) distinguishes two kinds of competences when perceiving humour. The first, joke competence, is related to recognition of a humorous text.

The second implicature, understanding humour, in addition to recognition, also involves perceiving the joke as humorous and amusing. Understanding the joke is demonstrated via certain support strategies by the recipient, like laughter or a comment (e.g. "I get it.") (Hay 2001). Silence, however, may imply that the humour was not recognised or understood. Failed humour may also be responded to with metalinguistic comments or comments evaluating either the speaker or the joke (Eisterhold 2007).

The third implicature, appreciation, expresses the recipient's positive attitude to the joke, perceiving it funny and amusing (Hay 2001). Laughter, echoing the speaker's words, overlapping and contributing more humour are unmistakable support strategies of appreciation. Carrell's (1997) second humour competence refers to the recipient's ability to judge whether the text is humorous. Sometimes, this competence may be distracted because of missing context or a "relevant script" (Ibid), for example, in the case of inside jokes.

The fourth implicature, agreement, denotes the recipient agreeing with messages associated with the joke. The implicature of agreement is essential when teasing or self-deprecating humour is being used (Hay 2001); each of them comprises a joke and a serious message (Alberts 1992) that may be a negative, critical or even an offensive judgement. The audience is expected to recognise and understand the joker's intention to be funny, but they are not obliged to appreciate or agree with it (Hay 2001). Manifestations of agreement denote acceptance of the humorous message and may be supported with laughter. The topics that are more sensitive (i.e., boundary humour or taboos), like religious beliefs, political or sexist views, (Carrell 1997) or ethnic origins, may cause different simultaneous responses. Hay (2001) explains it as a response of being offended and amused at the same time. This can be expressed by laughing while stating the message is offensive or cruel [i.e. disaster joke (Smith 2009)]. Such a situation implies recognition, understanding and appreciation, but excludes agreement (Hay 2001), and may therefore be left unsupported. An explicit response to disagreement is unlaughter, the term coined by Billig (2005: 192). Unlaughter is much more than the absence of laughter (Smith, 2009), it is a display of not laughing when laughter was expected, hoped for or demanded (Billig 2005: 192). It is withholding appreciation or agreement and rejecting the invitation to joke (Smith 2009).

Research on humour is interdisciplinary; it involves sociology and psychology, but also linguistics (Laineste 2010) - cognitive linguistics, pragmatics and semantics. As humour is part of verbal and non-verbal communication, cognitive linguistics and semantics play a crucial role in its investigation. An important factor impacting the perception and response to humour is the language of interaction. Bell and Attardo (2010) identified seven levels that are necessary for a humorous exchange not to fail:

- processing language at the locutionary level (i.e., surface meaning);

- understanding the meaning of words (including connotations);

- understanding the pragmatic force of utterances (including irony);

- recognising the humorous frame (either missing a joke or seeing a joke where none was intended); 
- understanding the incongruity of the joke;

- appreciating the joke;

- joining in the joking, supporting humour (mode adoption).

Not recognising these levels may result in failed humour. But failure may also be caused by the speaker's poor language skills, especially if the communicator is not a native speaker and uses a foreign language which makes difficult to perceive all the linguistic nuances.

Humour and laughter are universal, and they do not depend on people's cultural background. However, the topics that are made fun of and laughed at may be distinct depending on the person's cultural background. This depends on the intracultural and intercultural knowledge of humour, an individual's cultural competence and what is perceived as humorous by different ethnic groups (Sturges 2006). This is related to failed humour when the recipient has misunderstood the joke and interprets it as ironic or aggressive (Laineste 2010).

\subsection{Humour in tourism}

According to Frew (2006: 645), humour is conceptualised in the tourist experience in two main areas: informal humour - jokes are shared to cope with difficult, awkward or frustrating travel situations, and formal humour - the tourist attends an amusing and comedy-related event. In a wider sense, humour usage in services is divided into humour as an affiliative behaviour, humour as a coping behaviour and humorous service recovery (Mathies et al. 2016). The various factors to consider when using humour in tourism settings are also included in Pabel and Pearce's (2018) recommended seven-step framework for designing the tourism experience. Tourism companies mostly use humour to offer their customers comfort, connect with them and make them mindful and attentive to messages (Pabel \& Pearce 2019). Humour at accommodation establishments can be used on five different levels - situational, hidden, intended, designed and promised humorous communication (Piirman, Pratt, Smith, \& Tooman 2019). These different levels of humour can be used by tourism providers when there is a need to keep tourists' minds engaged and alert (Pabel \& Pearce 2016).

Tourists' perspectives on their perception and appreciation of humour have not yet been sufficiently researched. However, it is important to learn how humour can help create enjoyable and engaging experiences in tourism settings (Chiew, Mathies, \& Patterson 2018; Pabel \& Pearce 2016). According to Mathies et al. (2016: 148), "customers with a stronger sense of humour are more likely to enjoy a humorous interaction with service employees who use humour to create close relationships with them". It is within this context that this study is to understand the respondents' sense of humour and how this relates to their perception of the humour used in tourism companies.

\subsection{Sense of humour and its measurement}

A sense of humour is the reflection of a person's humour orientation. People who are high in humour orientation are commonly perceived as having a good sense of humour (Honeycutt \& Brown 1998). Sense of humour has been conceptualised from different perspectives: a habitual behaviour pattern, an ability, a temperamental trait, an aesthetic response, an attitude, a world view, or a coping strategy. These concepts may not be intercorrelated or relevant to positive psychology (Martin 2003). According to different classifications, humour may be verbal or nonverbal, intentional or non-intentional (Laineste 2010). The current study investigates humour as an intentionally presented written text (verbal messages) purposefully using different rhetorical tools to create incongruity - hyperbole, unexpected association, simile, anecdotal quote - to amuse the audience. However, in these situations it is not always possible to understand the 
speaker's efforts, which may result in failed humour, i.e., perceived as a neutral statement or verbal aggression.

In recent decades, more authors have found it important to study humour and its perception. Measuring humour and assessing its perception is a Herculean task. According to Kaindl (2004), humour is often studied through verbal dimensions. Despite the frequent criticism of questionnaires as only providing subjective and biased responses (Veenman 2005) or not assessing the specific ways individuals use or express humour (Martin, 2003), they are still the most widely used instrument. Martin and Lefcourt (1984) developed the Situational Humour Response Questionnaire (SHRQ) comprising 21 different situations for evaluation by respondents. Those who score high on the SHRQ are often extraverted, outgoing, friendly, realistic, enjoy excitement and risk-taking, laugh and smile and do not take themselves too seriously. On the basis of this outcome, Martin and Lefcourt proposed a definition for sense of humour as the frequency with which a person smiles, laughs, and otherwise displays mirth in a wide variety of life situations. In addition, the seven-item Coping Humour Scale (CHS) was developed (Martin \& Lefcourt 1983) to understand how individuals make use of humour to cope with stressful situations, while not actually measuring sense of humour (Martin, 1996). Thorson and Powell (1994) developed the Multidimensional Sense of Humor Scale that allows to study sense of humour in relation to mental issues, for example, finding that depression decreases as sense of humour increases. The Portuguese version of the MSHS scale consisted of three dimensions (Production of humour and social use of humour, Adaptive Humour and Appreciation of humour and Attitude Towards Humour) and has been confirmed suitable to study patients with chronic diseases (Sousa, Marques-Vieira, Severino, Pozo-Rosado, Antunes, \& José 2018).

Until the middle of the 1990s, many humour researchers used methods presenting respondents with jokes or cartoons that could be described as tests of humour appreciation. However, the fact that a person laughs does not give any information about whether a sense of humour could help them cope with difficult situations or how. McGhee's (1996) Sense of Humour Scale (SHS) included dimensions of enjoyment as humour, laughter, verbal humour, finding humour in everyday life, laughing at yourself, and humour under stress. Ruch and Heintz (2018) examined the psychometric properties of the SHS and highlighted that humour skills should be researched in more detail, as they cannot be mapped onto a single total sense of humour (SoH) factor. Svebak (2010) has been developing sense of humour measurement tools since 1969, introducing the Sense of Humour Questionnaire (SHQ) that combined 3 dimensions: meta-message sensitivity (M-items), liking of humorous situations (L-items) and mirthful expression (E-items), a shorter form (SHQ-6) including three items from the M- and the Ldimensions, and an ultra-short version (SHQ-3) that was used as part of a larger study. Sense of humour questionnaires were first used mostly in studies exploring the sense of humour in students but recently they have been used in wellbeing and health-related studies (Svebak 2010). The scope of the current research is perceiving humour in tourism and service situations. In order to better understand the respondents' perceptions in humorous situations, their sense of humour was assessed using the revised $(\mathrm{R})$ version of the questionnaire the SHQ-6-R (Svebak 1996).

\section{Methods}

The study was designed and conducted in two parts (Figure 1). Study I focused on representatives of tourism companies in Estonia (tourism service providers). Its research aim was two-fold - first, to clarify the use of humour tourism service providers perceive as appropriate to use in customer service. Second, they were asked to send examples of the use of 
written humour in interactions with their clients. Written humour (textual or pictures) was preferred because the data were collected with the written questionnaire that was not conducive to collecting data orally. Retelling oral humour in written form lacks the context, body language, facial expressions, and other aspects necessary to perceive the humour. These examples provided input for Study II, where authors investigated how potential visitors to Estonia perceive humour used in Estonian tourism companies.

\begin{tabular}{|c|c|c|c|}
\hline Study & Study I & & Study II \\
\hline Sample & $\begin{array}{l}\text { Tourism service } \\
\text { providers }\end{array}$ & & Potential tourists \\
\hline $\begin{array}{l}\text { General perceptions } \\
\text { of humour }\end{array}$ & $\begin{array}{l}\text { Perceptions of the } \\
\text { importance of humour }\end{array}$ & & $\begin{array}{l}\text { Sense of humour - SHQ- } \\
6-\mathrm{R}\end{array}$ \\
\hline \multirow{2}{*}{$\begin{array}{l}\text { Specific perceptions } \\
\text { of humour }\end{array}$} & $\begin{array}{l}\text { The use of humour in the } \\
\text { tourism company }\end{array}$ & & \multirow{2}{*}{$\begin{array}{l}\text { Estimation of the use of } \\
\text { humour }\end{array}$} \\
\hline & $\begin{array}{l}\text { Examples of their use of } \\
\text { humour }\end{array}$ & $\longrightarrow$ & \\
\hline
\end{tabular}

Figure 1. The design of the research

Study II examined how potential international visitors understood and perceived the humour used by Estonian tourism companies. Respondents' judgements of these jokes were researched in correlation with their sense of humour measured using the SHQ-6-R.

\subsection{Study I}

\subsubsection{Sample}

Study I included a sample of companies active in the Estonian tourism market. A list of Estonian tourism providers was obtained from Visitestonia.com. The invitation to participate in the research was sent via email to 3,413 contacts. The questionnaire was completed by 246 respondents, which is sufficient considering the confidence level of $95 \%$ and the confidence interval of 6\% (Israel, 1992). The respondents were classified according to the ten different categories used by Visitestonia.com. The most represented categories were accommodation (37\% of the respondents), catering and clubbing (17\%), culture and history (16\%) and adventure holidays (11\%). The category of transport was represented by only one respondent; and this was removed from the analysis. According to the region of operation in Estonia, 53\% were active in urban and $47 \%$ in rural areas.

\subsubsection{Data collection and analysis}

Data were collected using an online questionnaire (Appendix 1) disseminated through professional mailing lists and e-mails from the end of March till the end of April 2019 (on the $5^{\text {th }}$ of April, a repeat invitation was sent). Several replies were received where the respondents confirmed they had completed the questionnaire, informed us directly that they were not using humour, or explained how their humorous communication works only in context. A few replies were rather critical of our survey invitations, indicating that they were taking their business seriously and that using humour was considered as inappropriate and irresponsible.

The questionnaire included 6 questions about the respondents' evaluations of the importance of using humour in different marketing and communication media - advertisements, oral communication, informative texts, pictures, facial expressions, introductory video clips, and 
souvenirs (Pearce 2009). The respondents were also asked whether humour was intentionally used in their company. If yes, they were asked to provide examples. In total, 26 humour examples were sent, and 12 of them were selected for the follow-up study (Study II) (Appendix 2 ). The selection was based on the authors' estimation of the humorousness of the examples. The examples were textual and used in catering $(\mathrm{N}=6)$, accommodation $(\mathrm{N}=2)$, culture and history $(\mathrm{N}=1)$, adventure holidays $(\mathrm{N}=1)$, and everyday situations, i.e. toilets and smoking areas $(\mathrm{N}=2)$.

\subsection{Study II}

Study II aimed to estimate how potential tourists may understand and perceive the humour used in tourism companies in Estonia. The pool of humorous examples collected from the Estonian tourism companies in Study I was used as input for Study II, where the non-Estonian respondents assessed how humorous these examples were to them. In addition, all respondents completed the SHQ-6-R (Svebak 1996). This made it possible to compare the respondents' estimates of examples in correlation with their sense of humour.

\subsubsection{Sample}

Study II included a convenience sample of non-Estonian participants who could potentially visit different Estonian tourism companies. They were recruited to participate in this study between June 11th and July $11^{\text {th }}, 2019$. Both authors used their personal contacts with foreigners and membership in different international Facebook groups and e-mailing lists to share the invitation to the study. The sample consisted of 154 people, $67 \%$ female and 33\% male. The largest group of respondents by age were 31-40 years old (23\%), followed by $41-50$-year-olds with $19 \%$. Respondents were from 35 different nationalities. Ethnically, the largest groups were Latvians (13\%), Russians (12\%), British (10\%), Swedish (8\%), and Lithuanians (5\%), most of them Estonia's closest neighbours. They were followed by Americans (4.5\%), Finnish and Dutch (3.3\%), and Czech and Polish (both 2.6\%). The rest of the nationalities were represented by $1-$ 3 respondents.

\subsubsection{Data collection and analysis}

Data were collected using a two-part online questionnaire. The first part (SHQ-6-R) consisted of six statements reflecting cognitive, social and affective dimensions of the sense of humour. The respondents evaluated the statements on a 4-point scale (Appendix 2). Before analysing the data, the factor structure of the instrument was tested using a confirmatory factor analysis (Maximum likelihood), which provided acceptable model fit indices $\left(\chi^{2}=6,208 ; \mathrm{df}=5\right.$; $\mathrm{CMIN} / \mathrm{df}=1,242 ; \mathrm{CFI}=.989 ; \mathrm{RMSEA}=.04)$. The scores for the statements in the three dimensions were summarised. The total score reflects the sense of friendly humour.

The second part of the questionnaire presented twelve situations, texts and pictures, which had been collected from Estonian tourism companies (see Appendix 2). These examples had been used by the tourism companies to entertain visitors. The respondents were asked to indicate how humorous they thought these texts/pictures were (very humorous, fairly humorous, not very humorous, not humorous at all, I cannot understand it). The respondents could also leave comments with each text/picture.

In order to see whether the participants could be grouped based on their sense of humour and how, a cluster analysis was also conducted. The clusters were correlated with the estimates of the humorous examples to explore the participant's responses in relation to their sense of humour. Their comments on the humorous examples were analysed using thematic content analysis. 


\section{Results}

\subsection{Study I}

The first part of the study investigated how important tourism service providers considered the use of humour to be in communications with tourists (RQ1). In the data analysis, the two maximum scores (very important and important) were summarised as one positive answer. This was followed by neutral, not important and unacceptable.

Figure 2 reveals that using humour in oral communication was considered the most important (assessed important or very important in $72 \%$ of cases). This was followed by advertisements (53\%) and souvenirs (51\%). Using humour in textual material was rated as the least important $(26 \%)$, and this item was also rated as most unacceptable (16\%).

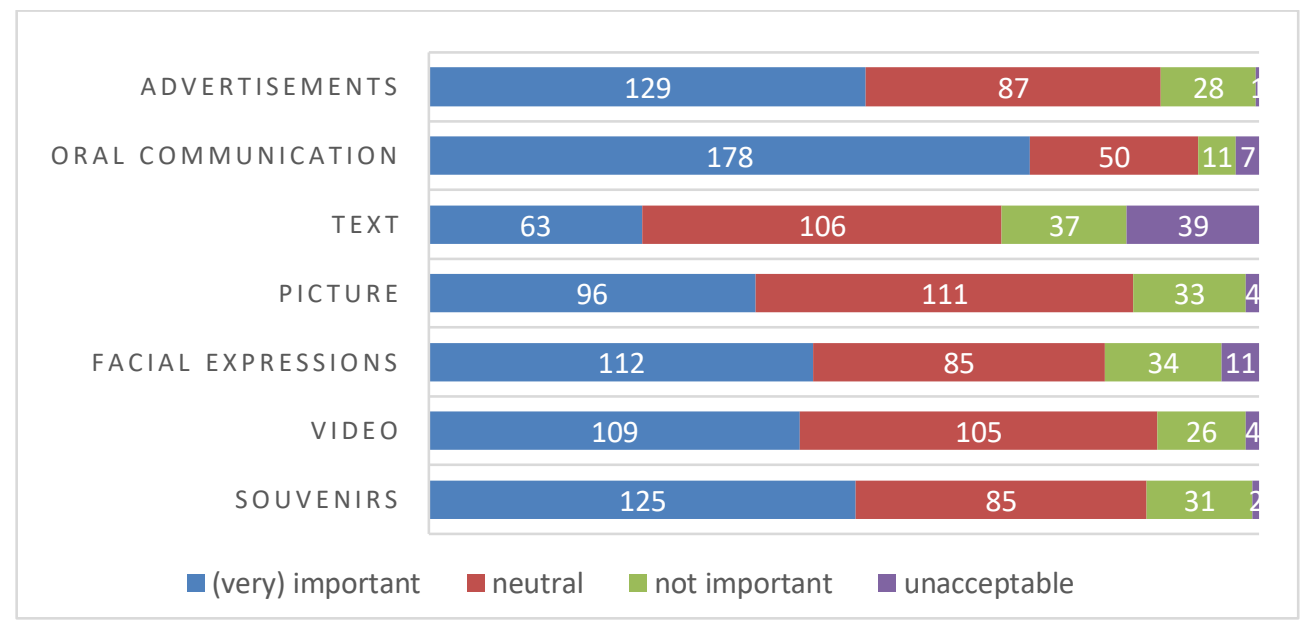

Figure 2. Tourism service providers' perceived level of importance of using humour in different types of media $(\mathrm{N}=246)$

If we observe these results within the different tourism categories, the importance of using humour in advertisements was considered highest by tourist information centres $(75 \%$ were assessed important or very important) and in culture and history (64\%). Oral communication was most highly estimated by the fields of catering (92\%) and active holidays and adventure $(88 \%)$. Using humour in textual materials was considered important only by spas and saunas $(57 \%)$, and in pictures by tourist information centres (75\%), and active holidays and adventure $(63 \%)$. Using humour in facial expressions was most highly estimated by active holidays and adventure $(79 \%)$, in videos by tourist information centres $(75 \%)$ and conference centres $(57 \%)$, and in souvenirs by active holidays and adventure (75\%), and conference centres (57\%). The comparative overview of the highest estimates in each category is revealed in Figure 3. 


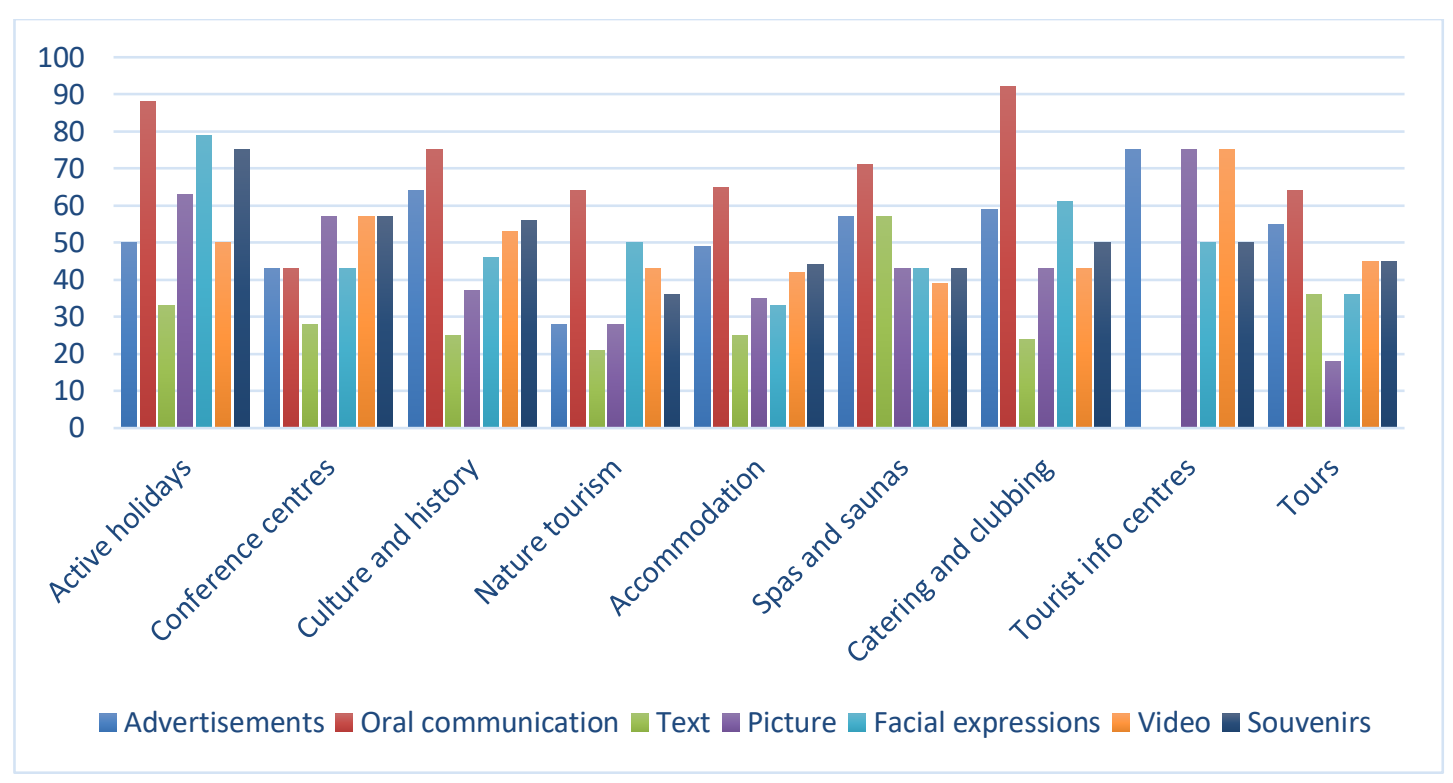

Figure 3. The various tourism categories and their preferred forms of humour

Comparing the tourism service providers' responses based on location (urban versus rural) revealed that the only differences were in the use of advertisements: $61 \%$ of the tourism companies in urban areas considered using humour in advertisements valuable (rural companies $43 \%$ ). Further differences were revealed in using text (urban 22\%, rural 31\%), and pictures (urban $44 \%$, rural $34 \%$ ).

Next, the respondents were asked whether humour was intentionally used in their company. Out of 246 companies, 71 (27\%) admitted using humour intentionally. Catering and clubbing, accommodation, and culture and history each represented $23 \%$, active holidays and adventure $16 \%$.

\subsection{Study II}

Study II sought to estimate how potential tourists perceived the humour used in Estonian tourism companies (RQ2). The respondents were asked to assess the humorous examples presented in 12 pieces of text on a 4-point scale: very humorous (4 points), fairly humorous (3 points), not very humorous ( 2 points) and not humorous at all (1 point). The answers for "I cannot understand" were eliminated from the analysis when the mean values were calculated. When assessing the humorous examples, the respondents could add open-ended comments to the form. This option was used by 47 people. These comments gave insight into the respondents' humour appreciation and enabled us to better understand their perception of the humorous examples. When analysing the answers, it must be remembered that all examples were presented without context and that this lack of context may have affected the participants' perceptions.

In the subsequent analysis, the jokes were grouped according to topic: religious jokes (No 1), pub jokes (No 2, 3, 4, 5, 10), ethnic-traditional jokes (No 6), Soviet-historical jokes (No 7, 9), bathroom jokes (No 8, 12), smoking jokes (No 11). The religious joke (see Appendix 2) was estimated very or fairly humorous by $48 \%$ of the respondents $(\mathrm{M}=2.35, \mathrm{SD}=0.85)$. The reason this was estimated relatively low was the rather frequent opinion that religion is not an appropriate topic to joke about as this may offend religious people. It was not considered funny but rather "strange and vaguely fascistic". The participants who disapproved of the religious joke were mostly female, aged 41-50, and of Russian or British origin.

The pub jokes were represented by five examples. The average evaluation of these jokes was $2.74(\mathrm{SD}=0.84)$, where example No 3 rated the lowest $(\mathrm{M}=2.25, \mathrm{SD}=0.92,38 \%$ very or 
fairly humorous) and example No 4 the highest $(\mathrm{M}=3.01, \mathrm{SD}=0.76,84 \%$ very or fairly humorous). The main critique concerning the pub jokes was that most of these were perceived as being too old, overexploited and now clichéd. Another serious reproach was about the poor wording and grammar, which might affect the perception of the joke and create the opposite effect. Eleven people out of 154 admitted not understanding this joke. However, the pub humour also received several positive comments; for example, "Most people like alcohol-related jokes and people are often so serious about their health, it is good to play around with it." (female, 41-50, British). If we view the comments according to respondent origin, we see the British were more critical of the pub jokes, while people geographically closer and historically similar to Estonia (Latvians, Lithuanians and Poles) appreciated these jokes more.

Humour example No 6 had ethnic-traditional content - using a smoke signal in clear weather $(\mathrm{M}=3.03, \mathrm{SD}=0.76,72 \%$ very and fairly humorous; 9 participants indicated that they did not understand it). The critical comments brought out its cultural dissonance, "It would be funny at an Indian casino hotel in America," (male, 41-50, British). However, a lot of respondents, mostly British, found it a safe joke, moderately funny and friendly.

Two humorous examples (No 7 and No 9) can be classified as historical, both focusing on the Soviet theme. Similar to the religious example, the Soviet(-ideology)-related humour caused diverse reactions. Joke No 7 on the five-year plan was rated higher $-\mathrm{M}=2.76, \mathrm{SD}=0.95$ (67.4\% very and fairly humorous); however, several comments were critical because the irony was not understood. "Many people, awarded the Hero of Socialist Labour, worked honestly and enthusiastically for the benefit of their great country - the Soviet Union. Modern post-Soviet people are primitively self-centred and can hardly appreciate this." (female, 60+, Russian).

On the other hand, for some participants the Soviet topic may be handled as a painful experience that is not remembered willingly. "It depends where you come from. Western people might find it funny but those who lived within the Socialist Bloc probably not, especially those over 45." (female, 41-50, British). A generation gap was pointed out as an obstacle to understanding these jokes. "Not for the millennials and younger generation. They have no idea what a five-year-plan is and it's not really enough to explain it to really get the joke." (female, 41-50, Latvian). Humour example No 9 about a closed-off city received low humour appreciation from participants $(\mathrm{M}=2.11, \mathrm{SD}=0.85,35 \%$ very and fairly humorous $)$, mostly because its poor wording and grammar made the humour attempts difficult to understand. In brief, it was not possible to distinguish the respondents' attitude towards these jokes based on their historical background. Ultimately, it seems to be a matter of "social sensitivity" that finetunes the perception of political humour.

Humour example No 11 was used to label a smoking corner in a guesthouse. Even though the respondents' humour appreciation was not low $(\mathrm{M}=2.53, \mathrm{SD}=1.03,55 \%$ very and fairly humorous), the comments were mostly critical - judgemental, vulgar, offensive, passiveaggressive - "Shaming smokers was never funny. They are also customers, and the smoking corner could be funny without making people feel marginalised." (female, 41-50, German). Several respondents also referred to a grammatical mistake.

The last category was based on bathroom humour examples (No 8 and 12), both of which were perceived as highly humorous, $\mathrm{M}=3.21, \mathrm{SD}=0.83$ ( $83.4 \%$ very and fairly humorous) and $\mathrm{M}=2.62, \mathrm{SD}=0.86$ (59\% very and fairly humorous) accordingly. No 8 was more positively commented on by men aged 41-50 - "Great play on words. Would make me chuckle and more likely to have the desired effect" - and negatively by women - "Again. Old. Lame. Oh, and I'm a woman, so...". The attitudes to the other bathroom joke (message on the mirror) were more neutral. However, a few respondents found it an inane and tedious cliché or "forcing a certain mode of behaviour" (male, 41-50, British). Others admitted it was philosophical as well as beautiful. 
In order to investigate whether the perception of the humour examples used in Estonian tourism companies (Appendix 2) related to the respondents' sense of humour (RQ3), the latter was assessed using the SHQ-6-R. The descriptive statistics (Table 1) reveal the highest mean values in the social dimension, and the lowest in the affective. According to Svebak, the social dimension refers to the individual's perception of his or her peers' sense of humour - how it is received, and how funny or irritating it is perceived to be.

Table 1. The descriptive statistics of the dimensions of the sense of humour

\begin{tabular}{|l|l|l|l|l|l|}
\hline & Number & Minimum & Maximum & Mean & $\begin{array}{l}\text { Standard } \\
\text { Deviation }\end{array}$ \\
\hline Cognitive dimension & 154 & 2 & 8 & 6.40 & 0.95 \\
\hline Social dimension & 154 & 4 & 8 & 7.04 & 0.97 \\
\hline Affective dimension & 154 & 3 & 8 & 6.13 & 1.30 \\
\hline
\end{tabular}

Next, a K-cluster analysis was conducted to ascertain how respondents were grouped according to their sense of humour, age and gender. For the K-cluster analysis, the data were checked for outliers, the data (sums of cognitive, social and affective dimensions) were standardised and different cluster solutions were checked. As the ANOVA did not reveal statistical significance for gender, it was eliminated from the analysis. As a result, we obtained a two-cluster solution (see Figure 4) with four significant variables.

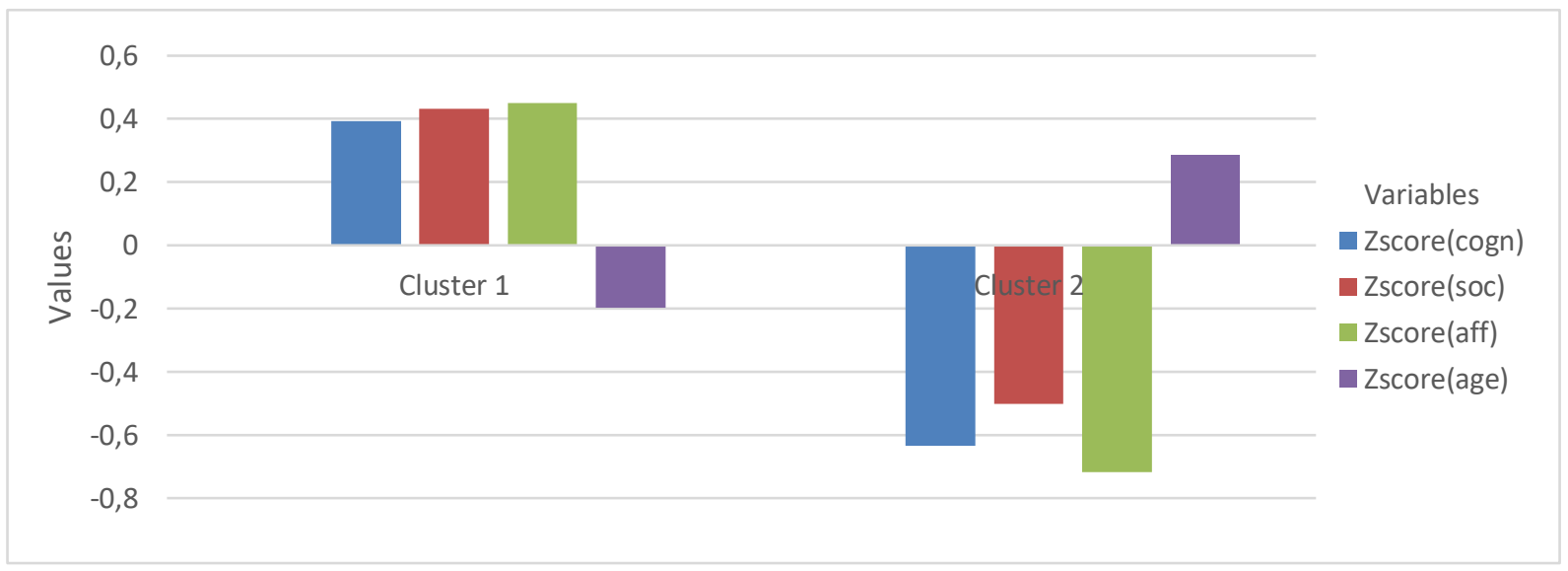

Figure 4. The two-cluster solution

Cluster $1(\mathrm{~N}=81)$ connected younger people with a higher sense of friendly humour (average sum $\mathrm{M}=20.9 ; \mathrm{SD}=1.38)$, whereas cluster $2(\mathrm{~N}=56)$ consisted of older participants with lower results in the sense of humour $(\mathrm{M}=17.36 ; \mathrm{SD}=1.45)$. When the cluster differences were analysed with the independent samples t-test, the results revealed statistically significant differences in the total scores [ $\mathrm{t}(135)=14.45 ; \mathrm{p}=.000]$ as well as in all three dimensions of humour (Table 2). 
Table 2. Differences between the clusters according to dimensions $(\mathrm{N}=137)$

\begin{tabular}{|l|l|l|l|r|r|}
\hline & $\begin{array}{l}\text { Cluster 1 } \\
\mathrm{M}(\mathrm{SD})\end{array}$ & $\begin{array}{l}\text { Cluster 2 } \\
\mathrm{M}(\mathrm{SD})\end{array}$ & $\mathrm{t}$ & $\mathrm{df}$ & $\mathrm{p}$ \\
\hline Cognitive dimension & $6.72(0.81)$ & $5.61(0.91)$ & 7.49 & 135 & .000 \\
\hline Social dimension & $7.46(0.78)$ & $6.55(0.83)$ & 6.51 & 135 & .000 \\
\hline Affective dimension & $6.72(1.09)$ & $5.20(1.05)$ & 8.15 & 135 & .000 \\
\hline
\end{tabular}

These findings reveal significantly higher scores in cognitive $\left(t=7.49^{*}\right)$, social $\left(t=6.51^{*}\right)$, and affective dimensions $\left(t=8.15^{*}\right)$ for younger people, which is due to their higher sense of friendly humour.

The Pearson correlation analysis between the clusters and the perceptions of humour revealed a significant, albeit weak, negative correlation with two humour examples: No 1 humour on religion $(r=-.262 ; \mathrm{p}<.05)$, and No 4 on pub humour $(\mathrm{r}=-.198 ; \mathrm{p}<.05)$. This refers to the younger people's higher appreciation of religion and pub humour compared to older participants who might consider religion inappropriate and pubs/drinking banal to joke about.

In conclusion, it appeared that several jokes lost effect because of poor translation or grammar. The safest humour examples by the tourism companies were based on bathroom jokes and it would be wise to avoid any humour attempts related to religion and a painful history. Why younger people might perceive these two examples as funnier than older people will be discussed below.

\section{Discussion}

The first part of the study aimed at clarifying the use of humour Estonian tourism service providers perceive as appropriate to use in customer service. The fact that humour is a powerful conversational tool (Bell 2006) was confirmed when the tourism service providers claimed that humour in oral communication was most important to them. Situational humour occurs spontaneously during interactions (Piirman et al 2019) and does not require a lot of preparation. The popularity of humorous oral communication in catering can be explained by people tending to appreciate it when someone amuses them, which could lead to more satisfied customers and bigger tips. Humour helps to connect with customers, and this has been found to be useful during tourism interactions because it keeps tourist audiences engaged and alert (Pabel \& Pearce 2016). Humour also helps recall important messages (Seneviratne \& Molesworth 2015), which is important when providing adventure related services.

Sending messages using funny facial expressions as a means of humour is another opportunity for active holidays and adventure service providers. The rather low use of humour among nature tourism providers in Estonia came as a surprise, since humour can be helpful for explaining, and helping people understand and remember, and therefore be a useful tool for educational and economic purposes (Ridanpää 2014).

While in accommodation establishments about half of the respondents claimed they use humour (Piirman et al 2019), only $27 \%$ of other tourism service providers stated having used humour in their organisation. Ball and Johnson (2011: 205) noted that conducting business is a serious matter, and this is potentially why conference centres, as one of the most businessoriented service providers, remain conservative and are willing to use humour mainly in souvenirs and videos. A funny souvenir or a humorous comment in an introductory video may be perceived as an amusing touch without compromising the general image of the conference business. 
An interesting finding was that Estonian tourist information centres ranked themselves highly for using humour in advertisements and pictures, while a study in Croatia found that only one DMO (Destination Management Organisation) used humour in their activities (Slivar, Periša, \& Horvat 2018). Framing a product in an interesting or surprising way might help get more attention (Berger \& Iyengar 2013); therefore, DMOs need to stand out in a competitive travel market, surprise people, exceed expectations and evoke interest. The fact that many tourism providers ranked the appropriateness of using humour in textual materials as the lowest deserves attention and further research.

This brings us to the findings of the second part of the study, where authors investigated how potential visitors to Estonia perceive humour used in Estonian tourism companies. The younger respondents demonstrate a higher sense of friendly humour, and refer to their general openness, lack of taboo topics, openness to black humour, and not being burdened by "painful history" (as one of the respondents declared). Older participants, on the other hand, seem to be more conservative, wanting to follow traditions and rules (e.g. death is not a topic to make fun of, religion is sacred, sex and toilet related topics are not discussed in public).

While discussing the respondents' reactions to the examples of humour, we look back at the four-implicature distinctions by Hay (2001). Recognition as the first implicature refers to the recipient's realisation of an attempt at humour. The second implicature, understanding, involves perceiving the joke as humorous and amusing. In the current case, we cannot distinguish recognition, as all examples were presented to the respondents as jokes. However, we can estimate the respondents' understanding based on the open-ended comments they attributed to the jokes. Humorous attempts, although aiming to amuse, may present a potential loss of face for both parties in communication: for the speaker when the joke falls flat, and for the recipient when the joke is not understood (Zajdman 1995). The findings revealed that in spite of the speaker's intention to be humorous, in several cases these intentions were not acknowledged. This was apparent in $11 \%$ of all responses since the participants ticked the response option for "I cannot understand". It should be acknowledged that all examples were presented without context, and that this lack of context may have affected the participants' humour appreciation. Carrell (1997) explains that a joke may not pass through one's joke or humour competence when the relevant script is unavailable to the audience. Failed jokes may also be caused by the speaker's poor language skills. Speaking English as a foreign language may entail poor wording or grammar, or the pragmatic force of the utterances may be unclear (Bell \& Attardo, 2010). According to the respondents' feedback, it seemed to be a frequent reason that the intended humour was not understood.

The third implicature, appreciation (Hay 2001), was expressed by many participants using the response option for "very humorous" and "fairly humorous". For example, the humour attempts based on pub jokes were appreciated and commented on as amusing. Considering the clusters differentiated respondents based on age, it appeared that younger people were slightly more amused by one pub joke (No 4) and the religious joke (No 1) than older people. This is explained by the fact that younger people consider the topic of religion less serious compared to the older generation, who do not think that religion should be made fun of. That kind of humour is not amusing for religious people but may offend them. For most Estonians, who are statistically one of the most secular people in the world (Ringvee 2014), religion is not a serious topic; therefore, they are not sensitive about religious jokes.

Another topic that is frequently considered a boundary topic is ethnicity (Carrell 1997). Making and understanding ethnic jokes assumes a knowledge of the cultural background, otherwise the joke may fail - the message may be misunderstood or misinterpreted. Making an ethnic joke in a different ethnic-cultural context may add extra value to it or result in incomprehension or reluctance. This was also the case with joke No 6, which was considered appropriate in an American-Indian context but not in Estonia. Several humour examples were 
not appreciated because they were perceived as being too old or clichéd. They were understood as jokes but were not appreciated as humorous. Similar to Norrick (1993) and Bell (2009), it appeared that the recipients showed their recognition and understood the joke but also indicated a lack of appreciation. Berger (1995) points out the element of surprise being important in the structure of humour. According to Raskin (1985), the element of surprise is raised by a punchline that may contain a new and at first sight incompatible mindset, or hyperbole, irony, legerdemain or wordgame which was the case in the bathroom humour example (No 8).

The fourth implicature, agreement (Hay 2001) is the most complicated to distinguish because of its two-fold effect: agreeing or disagreeing with the message, on the one hand, and being amused on the other. The following part of the discussion presents the humour examples that are based on so-called boundary humour and focus on more sensitive topics. The current study revealed several sensitive topics; religion, which is often considered a boundary topic, was handled above. The Soviet period is another more sensitive topic that met controversial estimates and opinions. The people who have experienced the former Soviet regime and are old enough to remember it may have controversial memories and feelings about Soviet humour attempts - from glorification to pain. For younger people or those having no personal contact with the Soviet Union (i.e., Westerners), Soviet-related jokes may fail because of missing context. However, several respondents from the former Soviet Union enjoyed the humour and irony targeted at the Soviet regime. If the recipient of the humour attempt is younger, he or she may not perceive the historical burden from the Soviet era. Therefore, joking about Soviet relics, such as the five-year plan, may not be a taboo for the joke teller but may fall completely flat for recipient. As the comments did not reveal any clear ethnic or age-related distinctions, the attitudes towards history-related jokes were based on the person's social sensitivity and the sense of social humour.

Another example that should be discussed in relation to agreement (or, rather, disagreement) is the humour example about the smoking corner. Even though the humour was found to be funny and amusing, the open-ended comments expressed that the participants showed disagreement in regard to judging smokers. The jokes that violated the expectations of politeness give rise to unlaughter (Smith 2009), especially from those who feel they are being targeted. While the humour attempts were presented as part of an online survey, they remained without support strategies (Hay 2001). Nevertheless, the bathroom joke led to "contributing more humour". The humorous frame was maintained and new jokes from the same context were added.

\section{Conclusion}

In this investigation, we aimed to gain a better understanding of the use of humour in tourism organisations in Estonia and assess the responses from potential tourists to humour attempts by the Estonian tourism companies. The findings confirmed that the use of humour by Estonian tourism organisations varies. Similar inconsistent results of humour appreciation were detected by the (potential) tourists - not all respondents valued the humour examples being used by different tourism service providers. Some of the negative perceptions towards humour used in the given examples were mostly caused by the poor or incomprehensible translation of the jokes from one language to the other, inappropriate topics for joking (e.g. religion or painful history) or the lack of novelty. The positive responses arose due to a sense of novelty or an unexpected twist. Younger and older participants, even though forming distinct clusters based on their sense of humour, did not reveal very different evaluations of the humorous examples used in this study. 
In conclusion, this study indicates that humour is perceived differently by different people. Considering this in the context of tourism where people come together from highly varied backgrounds, i.e., geographically, culturally and historically, with varied ages and senses of humour, we acknowledge the difficulty in providing humour that meets everyone's expectations or that, at least, does not offend anyone. This recognition becomes especially important during customer service interactions.

\section{Appendices}

Appendix 1. The questionnaire to tourism service providers on the perceptions of the importance of humour (Study I)

1. How important do you think using humour is in the following types of media?
a. Advertisements
b. Oral communication
c. Informative texts
d. Pictures
e. Facial expressions
f. Video
g. Souvenirs

(very important, important, neutral, not important, unacceptable, cannot answer)

2. Is humour purposefully used in your company when providing service?

(yes, no)

3. If you answered yes to the previous question, please give an example how humour is used in your company. Give an example of humour targeted at foreign clients with the description of the context where it is used.

4. What was the aim of using humour?

5. Which tourism category your company belongs to?

(Active holidays, Conference centres, Culture and history, Nature tourism, Accommodation, Spas and saunas, Catering and clubbing, Tourist info centres, Tours, Transport)

6. Where is your company located?

(in town, in the countryside)

Appendix 2. The humorous examples used by Estonian tourism service providers ${ }^{1}$

Joke No 1. A statement on the restaurant wall

"There is no God, only Chef remains"

\footnotetext{
${ }^{1}$ We would like to thank the tourism service providers who granted us permission to reproduce their humorous examples.
} 
Joke No 2. A picture in front of a restaurant

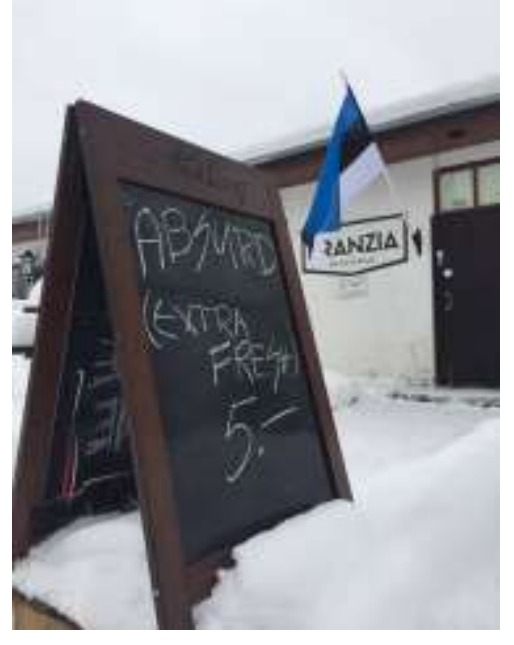

Joke No 3. A statement at the end of the menu

"true evil Estonian"

Joke No 4. A statement on the black chokeberry wine

"They say that chokeberries should lower your blood pressure, yet alcohol raises it. So you are well balanced"

Joke No 5. A statement at the bar

"It's gin o'clock"

Joke No 6. A statement at the hotel

"You can reach us by phone, email or sms and with very clear weather - a smoke signal!"

Joke No 7. A statement in the Soviet-time treasure hunt

"You have an hour to fulfil the five-year-plan and become the Hero of Socialist Labour!"

Joke No 8. A picture in a public bathroom

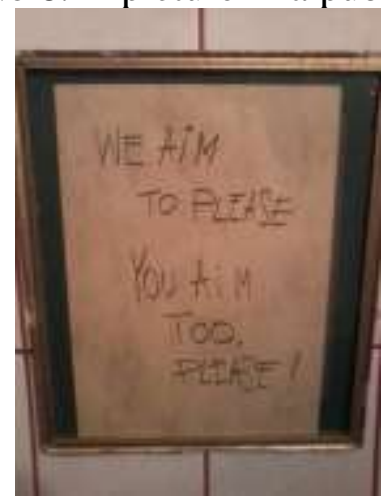

Joke No 9. A statement in an advertisement in the Sillamäe Museum

"Sillamäe Museum unlocks the secrets of the closed-off city" 
Joke No 10. A picture in a bar

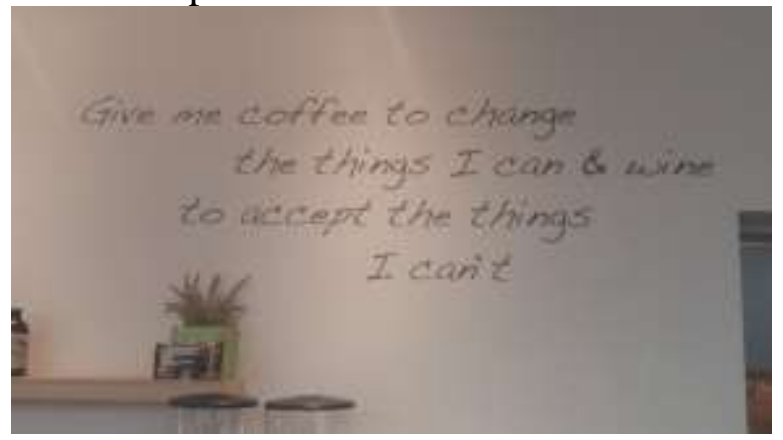

Joke No 11. A sign in the smoking corner

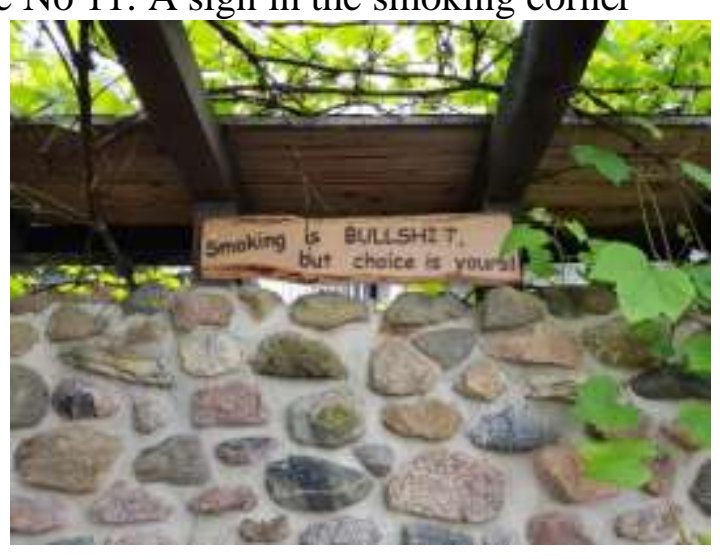

Joke No 12. A statement on the bathroom mirror

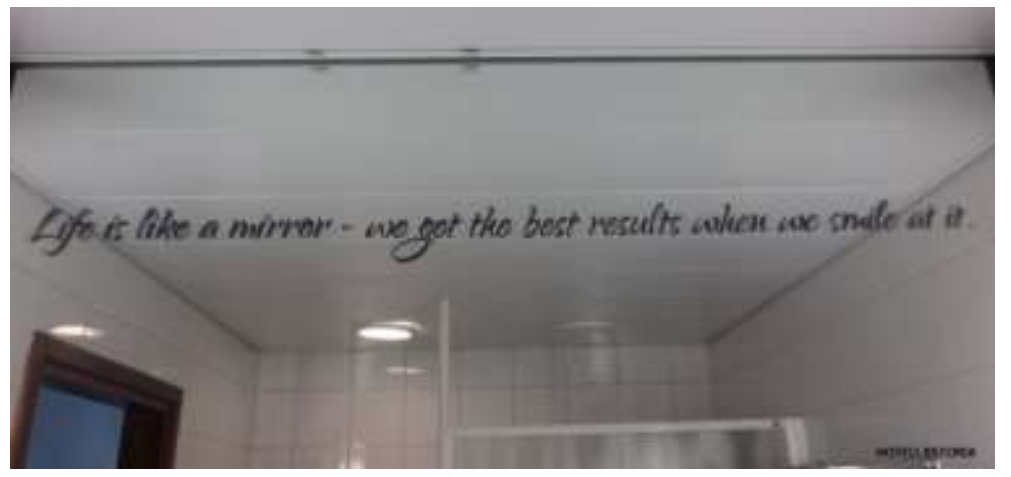

Appendix 3. SHQ-6 Revised (SHQ-6-R) (Study II)

\section{Instruction}

Describe your habitual attitude for each item by putting a mark in the box at the chosen alternative.

1) Do you easily recognize a mark of humorous intent?

Very easy $\quad$ Fairly easy $\quad \quad$ Fairly sluggishly $\square \quad$ Very sluggishly $\square$

2) Persons who are always out to be funny are really irresponsible types not to be relied upon.

Not at all $\square \quad$ To some degree $\square \quad$ To a high degree $\square \quad$ Yes indeed $\square$

3) Do you consider yourself to be a mirthful person?

Yes indeed $\square \quad$ To a high degree $\square \quad$ To some degree $\square \quad$ Not at all $\square$

4) Would you easily find something humorous in most situations if you really tried?

$\begin{array}{llll}\text { Very easy } & \text { Fairly easy } & \text { Fairly difficult }\end{array} \quad$ Very difficult $\square$

5) Humourists irritate me because they so blatantly revel in getting others to laugh. 
Not at all $\square \quad$ To some degree $\square \quad$ To a high degree $\square \quad$ Yes indeed $\square$

6) Do you easily smile and laugh?

\begin{tabular}{llll} 
Very easy & Fairly easy \\
\hline & Fairly difficult
\end{tabular}$\quad$ Very difficult $\square$

Developed by Dr Sven Svebak, Professor Emeritus, the Norwegian University of Science and Technology (NTNU), Department of Neuromedicine, Trondheim, Norway. (Contact: sven.svebak@yahoo.com). The SHQ-6-R can be used for free by students and academic staff for research, including masters and doctoral theses. The scale is not permitted to be used for commercial purposes, including personnel screening, recruitment etc. The copyright resides with Dr Sven Svebak.

\section{References}

Alberts, J. K. (1992). 'An inferential/strategic explanation for the social explanation of teases'. Journal of Language and Social Psychology 11 (3), pp. 153-177.

Alharthi, A. (2014). 'Humour and culture'. International Journal of Humanities and Cultural Studies 1 (3), pp. 119-130.

Ball, S. \& Johnson, K. (2011). 'Humour in commercial hospitality settings', in Lashley, C. \& Morrison, A. (eds.), Search of Hospitality: Theoretical Perspectives and Debates, London and New York: Routledge, pp. 198-216.

Bell, N. D. (2006). 'Interactional adjustments in humorous intercultural communication'. Intercultural Pragmatics 3 (1), pp. 1-28, doi:10.1515/IP.2006.001.

Bell, N. D. (2007). 'Humor comprehension: Lessons learned from crosscultural Communication'. Humor: International Journal of Humor Research 20 (4), pp. 367-387. doi: 10.1515/HUMOR.2007.018.

Bell, N. D. (2009). 'Responses to failed humor'. Journal of Pragmatics, 41, pp. 1825-1836.

Bell, N. \& Attardo, S. (2010). 'Failed humour: Issues in non-native speakers' appreciation and understanding of humour'. Intercultural Pragmatics 7 (3), pp. 423-447.

Berger, A. A. (1995). Blind Men and Elephants - Perspectives on Humor. New Jersey: Transaction Publishers.

Berger, J. \& Iyengar R. (2013). 'Communication channels and word of mouth: How the medium shapes the message'. Journal of Consumer Research 40 (3), pp. 567-579, doi:10.1086/671345.

Billig, M. (2005). Laughter and Ridicule: Towards a Social Critique of Humour. London: SAGE Publications.

Booth-Butterfield, M. \& Kanjeva, P. (2018). 'Extending humor enactment research'. Communication Research Reports $35 \quad$ (4), pp. 356-362, doi:10.1080/08824096.2018.1513835.

Carrell, A. (1997). 'Joke competence and humor competence'. Humor: International Journal of Humor Research 10 (2), pp. 173-185.

Chiew, T. M., Mathies, C. \& Patterson, P. (2018). 'The effect of humour usage on customer's service experiences'. Australian Journal of Management 44 (1), pp. 109-127, doi:10.1177/0312896218775799.

Eisterhold, J. (2007). 'Failed humor in American discourse'. Proceedings of the International Society for Humor Studies, Newport, RI.

Frew, E. (2006). 'The humour tourist: A conceptualisation'. Journal of Business Research 59 (5), pp. 643-646, doi:10.1016/j.jbusres.2006.01.004.

Grice, H. P. (1989 [1975]). 'Logic and conversation', in Studies in the Way of Words. Harvard University Press, pp. 22-40. 
Hale, A. (2018). 'I get it, but it's just not funny: Why humour fails, after all is said and done'. The European Journal of Humour Research 6 (1), pp. 36-61, doi:10.7592/EJHR2018.6.1.hale.

Hay, J. (2001). 'The pragmatics of humor support'. Humor: International Journal of Humor Research 14 (1), pp. 55-82.

Honeycutt, J. M. \& Brown, R. (1998). 'Did you hear the one about?: Typological and spousal differences in the planning of jokes and sense of humor in marriage'. Communication Quarterly 46 (3), pp. 342-352, doi:10.1080/01463379809370106.

Israel, G. D. (1992). 'Determining sample size'. University of Florida, PEOD6. Retrieved June 20, 2020 from https://www.gjimt.ac.in/wp-content/uploads/2017/10/2_Glenn-D.Israel_Determining-Sample-Size.pdf.

Kaindl, K. (2004). 'Multimodality in the translation of humour in comics', in Ventola, E., Charles, C. \& Kaltenbacher, M. (eds), Perspectives on Multimodality, John Benjamins: Amsterdam, pp. 173-192.

Laineste, L. (2010). 'Äpardunud huumor interneti kommentaarides' [Failed humour in Internet comments]. Keel ja Kirjandus 08-09, pp. 655-670.

Lynch, O. H. (2002). 'Humorous communication: Finding a place for humor in communication research'. Communication Theory 12 (4), pp. 423-445, doi:10.1111/j.14682885.2002.tb00277.x.

Martin, R. A. (1996). 'The Situational Humor Response Questionnaire (SHRQ) and Coping Humor Scale (CHS): A decade of research findings'. Humor: International Journal of Humor Research 9 (3-4), pp. 251-272.

Martin, R. A. (2003). 'Sense of humor', in Lopez, S. J \& Snyder, C. R. (eds), Positive Psychological Assessment: A Handbook of Models and Measures. APA Books, pp. 313-326, doi: 10.1037/10612-020.

Martin, R. A. \& Lefcourt, H. M. (1983). 'Sense of humor as a moderator of the relation between stressors and moods'. Journal of Personality and Social Psychology 45 (6), pp. 1313-1324.

Martin, R. A. \& Lefcourt, H. M. (1984). 'Situational Humor Response Questionnaire: Quantitative measure of sense of humour'. Journal of Personality and Social Psychology 47 (1), pp. 145-155.

Mathies, C., Chiew T. M. \& Kleinaltenkamp, M. (2016). 'The antecedents and consequences of humour for service: A review and directions for research'. Journal of Service Theory and Practice 26 (2), pp. 137-162, doi:10.1108/JSTP-09-2014-0187.

McGhee, P. E. (1996). Health, Healing, and the AMUSE System. Humor as Survival Training. Dubuque, IA: Kendall-Hunt.

Neuendorf, K. A., Rudd J. E., Palisin, P. \& Pask, E. B. (2015). 'Humorous communication, verbal aggressiveness, and father-son relational satisfaction'. Humor: International Journal of Humor Research 28 (3), pp. 397-425, doi:10.1515/humor-2015-0066.

Norrick, N. (1993). Conversational Joking: Humor in Everyday Talk. Indiana University Press, Bloomington.

Pabel, A. \& Pearce P. L. (2016). 'Tourists' responses to humour'. Annals of Tourism Research 57, pp. 190-205.

Pabel, A. \& Pearce, P. L. (2018). 'Selecting humour in tourism settings - A guide for tourism operators'. Tourism Management Perspectives 25, pp. 64-70, doi:10.1016/j.tmp.2017.11.005.

Pabel, A. \& Pearce, P. L. (2019). 'Humour in supplier-customer interactions: the views of Australian tourism operators'. The European Journal of Humour Research 7 (3), pp. 84100, doi:10.7592/EJHR2019.7.3.pearce1.

Pabel, A. (2019). 'Editorial: humour and its use in tourism contexts'. The European Journal of Humour Research 7 (3), pp. 1-5, doi:10.7592/EJHR2019.7.3.pabel. 
Pearce, P. L. \& Pabel, A. (2015). Tourism and Humour. Bristol: Channel View Publications.

Pearce, P. L. (2009). 'Now that is funny: Humour in tourism settings'. Annals of Tourism Research 36 (4), pp. 627-644.

Piirman, M., Pratt, S., Smith, M. \& Tooman, H. (2019). 'Assessing humour use in accommodation establishments: the Estonian context'. The European Journal of Humour Research 7 (3), pp. 63-83, doi:10.7592/EJHR2019.7.3.piirman.

Raskin, V. (1985). Semantic Mechanisms of Humor. Dordrecht: Reidel.

Ringvee, R. (2014). 'Religion: Not declining but changing. What do the population censuses and surveys say about religion in Estonia?' Religion 44 (3), pp. 502-515, doi: 10.1080/0048721X.2014.914635.

Ridanpää, J. (2014). 'Geographical studies of humor'. Geography Compass 8 (10), pp. 701-709, doi:10.1111/gec3.12159.

Rowe, A. \& Regehr, C. (2010). 'Whatever gets you through today: An examination of cynical humor among emergency service professionals'. Journal of Loss and Trauma 15 (5), pp. 448-464, doi:10.1080/15325024.2010.507661.

Ruch, W. \& Heintz, S. (2018). 'Psychometric evaluation of the revised Sense of Humor Scale and the construction of a parallel form'. Humor: International Journal of Humor Research 31 (2), pp. 235-257, doi:10.1515/humor-2016-0085.

Seneviratne, D. \& Molesworth, B. R. C. (2015). 'Employing humour and celebrities to manipulate passengers' attention to pre-flight safety briefing videos in commercial aviation'. Safety Science 75, pp. 130-135.

Slivar, I., Periša, A. \& Horvat, A. (2018). 'Destination marketing organisations' use of humour and co-creation: an exploratory study from Croatia'. Interdisciplinary Description of Complex Systems 16 (2), pp. 238-248, doi:10.7906/indecs.16.2.4.

Smith, M. (2009). 'Humor, unlaughter, and boundary maintenance'. The Journal of American Folklore 122 (484), pp. 148-171.

Sousa, L., Marques-Vieira, C., Severino, S., Pozo-Rosado, J. Antunes, A. V. \& José, H. (2018). 'Validation of the multidimensional sense of humor scale in people with chronic kidney disease'. Journal of Nursing Education and Practice 8 (3), pp. 72-79, doi:10.5430/jnep.v8n3p72.

Sturges, P. (2006). 'Limits to freedom of expression? Considerations arising from the Danish cartoons affair'. IFLA Journal 32 (3), pp. 181-188.

Svebak, S. (1996). 'The development of the Sense of Humor Questionnaire: From SHQ to SHQ6'. Humor: International Journal of Humor Research, 9 (3-4), pp. 341-361.

Svebak, S. (2010). 'The Sense of Humor Questionnaire: Conceptualization and review of 40 years of findings in empirical research'. Europe's Journal of Psychology 6 (3), pp. 288-310.

Thorson, J. A. \& Powell, F. C. (1994). 'Depression and sense of humor'. Psychological Reports 75, pp. 1473-1474.

Veenman, M. V. J. (2005). 'The assessment of metacognitive skills: What can be learned from multimethod designs?' in Artelt, C. \& Moschner, B. (eds), Lernstrategien und Metakognition: Implikationen fur Forschung und Praxis, Berlin: Waxmann, pp. 75-97.

Zajdman, A. (1995). 'Humorous face-threatening acts: Humor as strategy'. Journal of Pragmatics 23, pp. 325-339. 